\title{
An Empirical Study on the Omission of Third-Person Singular -s in Writing
}

\author{
Hongbo Qi ${ }^{1}$ \\ ${ }^{1}$ Eastern Institute of Technology Data Science and Communication College, Zhejiang Yuexiu University, China \\ Correspondence: Hongbo Qi, Eastern Institute of Technology Data Science and Communication College, \\ Zhejiang Yuexiu University, Shaoxing 312000, China. E-mail: 20141076@zyufl.edu.cn
}

Received: January 8, 2022

Accepted: February 17, $2022 \quad$ Online Published: February 27, 2022

doi:10.5539/ijel.v12n2p78

URL: https://doi.org/10.5539/ijel.v12n2p78

\begin{abstract}
Enlightened by studies in inflectional morpheme in L2 speech, this article reports a survey on the use of third-person singular $-s$ in writing by 6 L1 Chinese L2 English learners enrolled in Lancaster University in 2014. The results show that these undergraduate students omitted almost half $-s$ marking in obligatory contexts but made little or no mistake when they actually used third-person singular $-s$. The students were more successful in using be form than $-s$ form. The grammar of these students seemed to be "fossilized" in $-s$ marking since they made no improvement after attending a pre-sessional program at Lancaster University. Whiling echoing the findings of previous studies on either Chinese or other English learners (adults or Children), this article concludes that the acquisition third-person singular $-s$ is a challenge for adult Chinese English learners in writing. The implications for English language teaching in China are also discussed.
\end{abstract}

Keywords: fossilization, inflectional morpheme, second language acquisition, third-person singular $-s$, verbal inflection

\section{Introduction}

Omission of verbal inflection in L2 (Note 1) acquisition has become a focus of study in the field of second or foreign language research in recent decades (Zobl \& Liceras, 1994; Lardiere, 1998a, 1998b, 2000; Prevost \& White, 2000; Ionin \& Wexler, 2002; Franceschina, 2001; Yuan, 2001, 2003; Chang, 2005; Hopp, 2010; Jiang, Novokshanova, Masuda, \& Wang, 2011; Jensen, Slabakova, Westergaard, \& Lundquist, 2020; Nguyen \& Newton, 2021; Wakabayashi, Kimura, Matthews, Akimoto, Hokari, Yamazaki, \& Otaki, 2021; etc.). The explanations for the reasons behind this omission vary. According to Ionin and Wexler, there are two approaches to the issue: some researchers "attributes L2 learners' use of nonfinite verbs to an impairment of functional categories and/or features in L2 grammar" (Ionin \& Wexler, 2002, p. 99), while other researchers argue that "the grammar of L2 learners contains abstract categories and features and that the problem lies in mapping from the abstract feathers to the corresponding surface morphology" (ibid, p. 100). In Chang's (2005) term, the first approach to the issue is actually based on Failed Functional Features Hypothesis, while the second one is based on Missing Surface Hypothesis. Jensen et al. (2020, p. 3) argues that acquiring properties of the functional morphology is the most challenging part of learning a second language. Wakabayashi et al. (2021, p. 735) suggests that some verbal morphemes are extremely difficult to acquire in learning English, a typical example is third-person singular $-s$.

While the argument continues, we find most of the studies up till now have been focused on L2 speech. As teachers of English as a foreign language for several years, we often find similar situation in our students' writing. However, we are not very sure how serious the issue is in their written output. Due to this very reason, we are interested in finding out whether omission of verbal inflection really exists in L2 English writing by Chinese students. If yes, how serious is the situation? We will certainly discuss the possible reasons for what we will find, but again we will focus on a discussion of the implication for English language teaching in China. Owing to the limit of time and data available, we are especially interested in finding out whether the acquisition of third-person singular $-s$ is difficult for Chinese L2 English learners. Our subjects are some L1 Chinese students enrolled in Lancaster University in 2014. Our data comes from LANCAWE, Lancaster Corpus of Academic Written English.

The article is made up of four parts. In the second part of this report, we introduce the background of our study; 
our focus of the part is a review of the studies by Ionin and Wexler (2002) and Lardiere (1998a, 1998b). In the third part, we elaborate on the current study in terms of the purpose (followed by hypothesis), the subjects, the methods and the results of our survey. We discuss the results of the survey and possible explanation for the findings in the fourth part of the article. In the last part, we draw a tentative conclusion and point out the implication of our survey for English Language teaching in China.

\section{Theoretical Background of the Survey}

In order to find out whether syntactic and morphological development go side by side in L2 acquisition, Lardiere (1998a, 1998b) carried out a 9-year longitudinal study on Patty, an adult Chinese L2 speaker of English who had been living in the USA for nearly 19 years and had been fully exposed to L2 English-speaking environment for at least eight-and-a-half years since the first recording (Lardiere, 1998a, p. 12). The data Lardiere (1998a, 1998b) examined was based on three audio recordings (conversation with Patty) taped when Patty had been living in the United States for about 10 years, 18 years, and 18-and-a-half years respectively. Besides other discoveries such as evidence in verb-raising, two of the main focuses are the evidence of Patty's rate of suppliance of past tense marking -ed and agreement marking on third-person singular $-s$ in obligatory context. Table 1 summarizes the result of Lardiere's (1998a; 1998b) study. As can be seen, the results showed that Patty's rate of using of -ed marking in obligatory context was as low as approximately $34 \%$. Still worse was the fact that she was using $-S$ marking between $0 \%$ and $4.76 \%$ at the same time. Meanwhile, Lardiere also surveyed the suppliance of pronominal case marking (Table 2), and indicated that "we do not find a single incorrect choice of subject pronoun case" (Lardiere, 1998a, p. 17).

Table 1. A summary of suppliance of verbal inflection in obligatory context in Lardiere (1998a, 1998b) study

\begin{tabular}{lll}
\hline Recording & $-e d$ marking & $-s$ marking (in thematic verbs) \\
& Suppliance/Contexts (percentage) & Suppliance/Contexts (percentage) \\
\hline 1 & $24 / 69(34.78 \%)$ & $2 / 42(4.76 \%)$ \\
2 & $191 / 548(34.85)$ & $0 / 4(0.00 \%)$ \\
3 & $46 / 136(33.82)$ & $1 / 22(4.54 \%)$ \\
\hline
\end{tabular}

Table 2. Nominative form chosen as subject of a finite clause (Lardiere, 1998a, p. 18)

\begin{tabular}{lll}
\hline Recording & Nominative subject pronouns/finite past contexts & $\%$ \\
\hline 1 & $49 / 49$ & 100 \\
2 & $378 / 378$ & 100 \\
3 & $76 / 76$ & 100 \\
\hline
\end{tabular}

Based on the above facts, Lardiere argued that "we again find confirmation of a robust dissociation between the development of inflectional affixation and syntactic knowledge of formal features" (Lardiere, 1998b, p. 369).

To find out the reason behind omission of $-s$ marking in L2 acquisition, Ionin and Wexler (2002) studied speech samples from 20 L1 Russian children who were living in the USA or Canada and acquiring/learning English there. The children ranged in age from 3 to 13 and varied in length (most of them less than 3 years) of staying in the USA or Canada. The children were able to speak and understand English at the time of study. The data they collected were conversations with each child which lasted 30-60 minutes. The topics of the conversations included talking about their friends or schoolwork, and describing pictures in storybooks.

The results of their study were illustrated in Tables 3 and 4. As can be seen from Table 3, learners produced nonfinite forms in place of finite forms with omission of inflection high across categories. A note to be added is that the categories of irregular past-tense verbs or irregular third-person forms (e.g., has) were not counted in Table 3. Table 4 gave evidence to the fact that there were very few tense/agreement errors in the data. Table 3 also gave support to their hypothesis that the learners were more successful in the acquisition of suppletive agreement (be auxiliary and be copula) than that of affixal agreement (third-person $-s$ and past tense -ed).

Table 3. Omission of morphemes in obligatory contexts (Ionin \& Wexler, 2002, p. 106)

\begin{tabular}{llllll}
\hline & Third person $-s$ & Past tense $-e d$ & be auxiliary & be copula & All \\
\hline Number of omissions in obligatory contexts & 250 & 101 & 158 & 69 & 578 \\
Percentage of omission over all obligatory context & 78 & 58 & 33 & 16 & 41 \\
\hline
\end{tabular}


Table 4. Tense/agreement errors in morpheme use (Ionin \& Wexler, 2002, p. 107)

\begin{tabular}{lllll}
\hline & Third person $-s$ & Past tense $-e d$ & be auxiliary & be copula \\
\hline Number of instances of inappropriate use & 4 & 0 & 21 & 33 \\
Percentage of inappropriate use over all obligatory context & 5 & 0 & 7 & 9 \\
\hline
\end{tabular}

Before introducing our study, we must acknowledge that the forementioned literature is only part of the two studies by Lardiere (1998a, 1998b) and Ionin and Wexler (2002), in which they tried to prove the correctness of Missing Surface Hypothesis and to suggest a morphological approach to the discrepancy between L1 and L2 acquisition. We are not quite sure of the correctness of their studies as there are also other scholars (for example, Franceschina, 2001) who challenged the morphological approach by providing some new data collected from a near-native L2 speaker of Spanish Martin who seemed to have no problem with past forms, but have difficulty in case-marked forms. However, we found that both studies are based on spoken data, and neither study provided information about adult learners at school. As teachers of English for years, we are more interested in finding out whether omission of verbal inflection (especially the third-person singular $-s$ ) in L2 acquisition also appears to be an issue for adult Chinese L2 English learners. The following part introduces our survey based on data from LANCAWE.

\section{Current Study on the Use of -s Marking in the Writing of Chinese English Learners}

As has been pointed out in introduction of this article, the purpose of our study is to find out whether the third-person singular $-s$ is extremely difficult for Chinese English learners to acquire.

\subsection{Hypothesis}

Based on the previous sudies by Lardiere (1998a, 1998b), Ionin and Wexler (2002), Nguyen and Newton (2021) and Wakabayashi et al. (2021), indicating that morphological inflection is a big problem for many L2 English or EFL learners (adults or children) in speech and writing, we made four similar hypotheses for adult Chinese English learners.

Hypothesis 1: The L2 learners will produce nonfinite forms in place of finite forms in their writing.

Hypothesis 2: There will be little or no incorrect finiteness inflection in the writing of the L2 learners

Hypothesis 3 The L2 learners will be more successful in the acquisition of suppletive agreement than of affixal agreement.

Hypothesis 4 The issue of omission of affixal agreement $-s$ cannot be solved even after an intensive training course like the Presessional Program at Lancaster University.

For the first hypothesis, we will survey the omission of $-s$ marking, be auxiliary and be copula in obligatory context and calculate the percentage of omission over all obligatory contexts.

For the second hypothesis, we will count the number of inappropriate uses of $-s$ marking, be auxiliary and be copula and calculate the percentage of misuse over all instances.

For the third hypothesis, we will compare learners' grasp of suppletive agreement with that of affixal agreement in $-s$.

For the fourth hypothesis, we will compare the L2 English/EFL learners' omission percentage of $-s$ marking before and after the Presessional Program at Lancaster University.

\subsection{Methods}

\subsubsection{Subjects}

The subjects in this study were six L1 Chinese undergraduate students enrolled in Lancaster University in 2014. Before coming to the U.K., they had been learning English as a foreign language in China for at least 8 years. They are enrolled in the presessional program either because their total IELTS (International English Language Testing System) score was below 6.5 or because the total score reached 6.5 but at least one of the sub-skills scores below 6. Of the six subjects we studied, five of them scored 6.0 in IELTS, one scored 6.5, but her speaking was only 5.0. All of six students (two males and four females) were randomly selected from a group of 43 Chinese undergraduate students who attended a one-month presessional program and took the tests (T2 and T3).

\subsubsection{Data Collection}

English writing samples were obtained from each of the six Chinese students who attended a one-month 
presessional program at Lancaster University. Their writings during that period were recorded in LANCWE. The corpus contains five pieces of writing produced over four weeks by each of these students: two tests (T2 and T3) and three assignments (A4-A6). The tests data were selected since we thought they were more natural than the assignments as they were written within a limited time. We learned that the writing tasks completed under test conditions in 2014 were three retired IELTS academic writing tests, each containing a descriptive task (Task 1) and an argumentative task (Task 2). As task 1 usually requires test-takers to describe or explain one or some tables/graphs within about 150 words, we think it is not representative in indicating the examinees' writing capability. Therefore, we selected two writings (Task 2 in T2 and T3) for each of the 6 students as we consider these data to be long (at least 250 words per task) and representative (without too many constraints on test-takers) enough.

The data (12 argumentative tasks by 6 Chinese students) were downloaded from LANCWE website and jointed together in a plain-text format with all the errors kept intact. The results used to certify hypotheses 1 to 3 came from T2 (6 texts in all), and the both T2 and T3 (12 text in total) were used to testify hypothesis 4.

Although Ionin and Wexler distinguished regular thematic verbs from irregular ones like "does" and "has", as they indicated in their study (Ionin \& Wexler, 2002, p. 109) that the difference is not very significant, we decide to include "does" and "has" in the counting of $-s$. Another note is that we do not include -ed marking in our study because of lack of data. Formulaic expressions (e.g., you know) were not counted or computed.

\subsection{Results}

\subsection{1 -s Omission}

We firstly examined the use of three types of verbal inflection morphemes in obligatory context: the third-person singular $-s$, be auxiliary and be copula in 6 texts selected from Test 2 (T2). As is mentioned above, slightly different from what Ionin and Wexler (2002), we did not distinguish irregular verbs in third-person (e.g. has, does) from regular verbs. Table 5 gives the number of omissions in obligatory contexts, the total number of obligatory contexts and percentage of omission over all obligatory contexts.

Table 5. Omission of morphemes in obligatory contexts

\begin{tabular}{llll}
\hline & Third person $-s$ & be auxiliary & be copula \\
\hline Number of omissions in obligatory contexts & 14 & 1 & 4 \\
Total number of obligatory contexts & 29 & 4 & 46 \\
Percentage of omission over all obligatory contexts & 48.28 & 25.00 & 8.70 \\
\hline
\end{tabular}

As Table 5 shows, the rate of omission of third-person $-s$ in obligatory context was $48.28 \%$. At first glance, the figure is not high as compared with that of Table 1. Yet as the learners in our study had been learning English at school for at least 8 years and had a total IELTS score of at least 6 , this number is really high. Therefore, our first hypothesis that the L2 learners will produce nonfinite forms in place of finite forms in their writing is supported. An example such error is given below:

1). So if every body own at lease one car, it would be much crowder and we just have a limit place, how can we make such a lot land for the cars?

\subsection{2 $-s$ errors}

We also counted the number of errors in third-person $-s$, be auxiliary and be copula in contrast to the total number of their actual use. Table 6 gives the results of tense/agreement errors in morpheme use.

As can be seen from Table 6, percentage of inappropriate use over all instance of use in both suppletive agreements is $0.00 \%$, and in affixal agreement $-s 9.09 \%$. Similar to the results of Table 2 , the figures are very low. Nevertheless, our second hypothesis that there will be little or no incorrect infiniteness inflection in the writing of the L2 learners is supported. As a matter of fact, there is only one instance of inappropriate use of $-s$ agreement, which is given below:

2). We should open our mind and keep it up to date, then we can become the more modern people and help the technology develops more quicker. 
Table 6. Tense/agreement errors in morpheme use

\begin{tabular}{llll}
\hline & Third person $-s$ & be auxiliary & be copula \\
\hline Number of instances of inappropriate use & 1 & 0 & 0 \\
Total number of instances of use & 11 & 3 & 37 \\
Percentage of inappropriate use over all instances of use & 9.09 & 0.00 & 0.00 \\
\hline
\end{tabular}

\subsubsection{Use of Be Forms vs. Use of $-s$ Verbal Inflection}

As Table 5 indicates, the percentages of omission of be auxiliary, be copula and third-person $-s$ in obligatory contexts are $25.00 \%, 8.7 \%$ and $48.28 \%$ respectively. Considering the fact that the total number of obligatory contexts for be auxiliary is only 4 , the figure $25 \%$ does not make much sense. If we combine the number of omission in obligatory contexts for be auxiliary and be copula, the percentage of omission over all obligatory contexts for suppletive $-b e$ form will be $10 \%\{[(1+4) /(4+46)] \times 100 \%=50 \%\}$. The discrepancy between $10 \%$ error in be form and $48.28 \%$ error in $-s$ form is significant. Thus, our third hypothesis that L2 learners will be more successful in the acquisition of suppletive agreement than of affixal agreement is supported. Examples of omission of be auxiliary and be copula in our data are given below:

3) a. Omission of be auxiliary (the only case available)

This kind of traditional culture will ø living as long as the world be on the opposite side, it will lost.

b. Omission of be copula

Secondly, more and more cars on the road nowadays make the people who $ø$ always on foot in danger when they walk the road, especial the children and olders.

\subsubsection{Changes of Omission of $-s$ Marking Before and After an Intensive Training Course}

As Lardiere (1998a; 1998b) suggested, Patty's suppliance of past tense morpheme in obligatory contexts "fossilized" at a very low rate of approximate $34 \%$ over nearly 9 years of partially or fully exposure to L2 English environment. That is to say, she made about $66 \%$ error of -ed marking in obligatory contexts. Enlightened by this finding, we presupposed that Chinese English learner would not achieve any significant improvement even after an intensive Pressional Program at Lancaster University. Table 7 illustrates the result of this longitudinal study.

Table 7. Omission of $-s$ in obligatory contexts before and after presessional program

\begin{tabular}{lll}
\hline & Third person-s (Pre-programme) & Third person-s (Post-programme) \\
\hline Number of omissions in obligatory contexts & 14 & 11 \\
Total number of obligatory contexts & 29 & 22 \\
Percentage of omission over all obligatory contexts & 48.28 & 50.00 \\
\hline
\end{tabular}

As Table 7 shows, the percentage of omission over all obligatory contexts by the subjects were $48.28 \%$ before they attended the Presessional Program, yet the figure did not change much $(50.00 \%)$ by the end of the program. Thereupon, our fourth hypothesis that the issue of omission in affixal agreement cannot be solved even after an intensive training course like the Presessional Program at Lancaster University is supported. We will discuss all the results mentioned above in next part.

\section{Discussion}

The results given in the previous part show that adult Chinese English learners produced high rate (nearly $50 \%$, as indicated in Tables 5 and 7) of errors in employing $-s$ marking in obligatory context in their writing. This should not have happened considering the fact that the learners had been learning English in China for at least 8 or 9 years and writing is usually thought to be formal and involves self-monitoring and self-correction in the process. Although Patty (Lardiere, 1998a, 1998b) made about 66\% errors (approximately 34\% suppliance) of -ed marking and over $95 \%(0.00 \%$ to $4.76 \%)$ errors of $-s$ marking in obligatory contexts (Table 1), the Russian Children (Ionion \& Wexler, 2002) made 78\% errors of $-s$ marking and 58\% errors of -ed marking in obligatory contexts (Table 3), they are errors in speech after all. As teachers of English for several years, we know Chinese students make much more mistakes in $-s$ agreement in speaking than in writing; we never expected the situation to be so serious. Meanwhile, similar to what Lardiere (1998a, 1998b) and Ionion and Wexler (2002) had indicated, we also found the students were "competent" enough to use $-s$ marking when they actually used it. According to Table 6, only one inappropriate use of $-s$ out of eleven $(9.09 \%)$ instances of use was found. A 
further study of the example (2) in 3.3.2 indicates that the use of "develops" might be a result of "attraction of verb agreement" by its adjacent noun "technology" as described by Bock et al. (2001). In this sense, the writer still remembered to observe the rule for third-person singular $-s$, though he failed in achieving correct expression by misunderstanding the role of "technology" in the context.

The students in our data obviously had some difficulty in observing the rule for agreement in third-person singular $-s$ in obligatory contexts, meanwhile they also somewhat "knew" the rule since they were able to use $-s$ marking correctly once they actually decided to use it. According to Ladiere, this suggests that "syntactic and morphological developments are autonomous in L2 acquisition" (Ladiere, 2000, p. 120). However, she also acknowledged that "much work is still needed in order to understand the complex algorithms which map syntax to morphology" (Ladiere, 1998a, p. 23). Perhaps Hopp is right when he suggests "non-native and native grammars and processing systems are fundamentally identical, with L2 systems being computationally less efficient due to L1 influence" (Hopp, 2010, p. 901).

We have also noticed from the results of both Table 5 and Table 6 that the subjects in our study made more errors in third-person singular $-s$ in obligatory contexts (48.28\%) than be form (auxiliary and copula) as a whole $(25.00 \%, 8.7 \%$ respectively, and $10 \%$ in total) in their writing. Although the figures comparatively decreased as compared with that of Table 3, the results echo what Ionion and Wexler (2002), Nguyen \& Newton (2021), and Wakabayashi et al.(2021) suggested in that L2 learners are more successful in the acquisition of be form than $-s$ form. Zobl and Liceras compared the order of acquisition in L1 and L2, and found out that different from L1 learners, L2 learners acquire auxiliary be prior to third-person singular $-s$. Both L1 and L2 learners acquire copula be prior to third-person singular $-s$ (Zobl \& Liceras, 1994). In other words, L2 learners acquire be form prior to third-person $-s$ form. For Lardiere, "the maping from feature to form is arguably much 'easier' for case on pronouns (in English) than for tense and agreement on verbs" (Lardiere, 1998a, p. 22). Ionin and Wexler suggested that "L2 learners initially associates morphological agreement with verb-raising and, thus, acquire forms of be before inflectional morphology on in situ thematic verbs" (Ionin \& Wexler, 2002).

Table 7 gives evidence that Chinese English learners made almost no improvement in verbal agreement in English after a one-month presessional program at Lancaster University. We could not infer from the study that the presessional program was a failure because we did find evidence of improvement in students' writing in terms of more complex structures and richer vocabulary applied in T3 than in T2. However, we might be able to conclude from our study that the grammar of these Chinese learners seems to have "fossilized" with regard to $-s$ marking. According Wu (2001), there are two approaches to the explanation of fossilization in L2 acquisition: one attributes this to the miss of "critical period", the other believes that there exists "a latent language structure" in every learner, L2 grammar is fossilized only because the structure has not yet "reactivated". As teachers of English, we are more inclined to believe that education is capable of reactivating the latent language structure in our students. We will further discuss this point in next part.

\section{Conclusion and implication}

Before drawing a conclusion, we would like to point out the limitations of our study.

Firstly, owing to the limit of time and data, the result of our study will by no means be comprehensive and representative as only 6 subjects and 12 texts are examined.

Secondly, most literature in this aspect study more natural language such as speech while we studied written language which might or might not be suitable for second language study as far as the applicability of UG in L2 is concerned.

However, this study does find something interesting. Omission of $-s$ marking in obligatory contexts did exists in L1 Chinese L2 English learners at a high rate (nearly 50\%) though they made little or no mistake when they actually used third-person $-s$. The students were more successful in using be form than $-s$ form. The grammar of these Chinese learners seems to have "fossilized" with regard to $-s$ marking. In short, what some other researchers have found concerning $-s$ morpheme in speech also exists in written English. Third person singular $-s$ is proved to be a big challenge for Chinese English learners.

Implication can be drawn for language teaching in China:

In China, Children differ in age when they are taught English. As far as we have learned, in some developed provinces, children are taught English in kindergarten while in some underdeveloped provinces, children begin to learn English at least 13 years old because of financial reasons. If "critical period" does exist, then policy-makers need to reconsider the situation.

In order to make the textbook easy to learn, as we find out, most texts and tasks used in our class are usually 
adapted in a way that they are not authentic. As a result, Chinese students are either misled or bored with the uninteresting texts and impractical tasks. Therefore, with unauthentic texts and tasks, how can the "latent language structure" be "reactivated"?

As teachers of English for years, we also notice that with the advent of communicative approach (which was introduced to China in 1990s), language teaching and learning in China are more meaning-oriented rather than structure-oriented (which might be a result of misunderstanding of communicative approach). We used to think that "He goes to school at 7 every morning" is as easy as "He is a student" in either meaning or structure. However, the results of our study show this is not true. Therefore, equal attention should be paid in English class in meaning and form. Meanwhile, much needs to be done in finding out reasons behind the omission of inflectional morpheme in spoken and written output, and ways to prevent students from "fossilizing" their grammar in affixal morpheme like $-s$.

\section{References}

Bock, K., Eberhard, K. M., Cutting, J. C., Meyer, A. S., \& Schriefers, H. (2001). Some attractions of verb agreement. Cognitive Psychology, 43(2), 83-128. https://doi.org/10.1006/cogp.2001.0753

Chang, H. (2005). Missing inflections and impairment of interlanguage grammar. Modern Foreign Languages (Quarterly), 28(1), 61-71.

Franceschina, F. (2001). Morphological or syntactic deficits in near-native speakers? An assessment of some current proposals. Second Language Research, 17(3), 213-237. https://doi.org-/10.1177/026765830101700301

Hopp, H. (2010). Ultimate attainment in L2 inflection: Performance similarities between non-native and native speakers. Lingua, 120, 901-931. https://doi.org/10.1016/j.lingua.2009.06.004

Ionion, T., \& Wexler, K. (2002). Why is 'is' easier than '-s': acquisition of tense/agreement morphology by child second language learners of English. Second Language Research, 18(2), 95-136. https://doi.org/10.1191/0267658302sr195oa

Jensen, I. N., Slabakova, R., Westergaard, M., \& Lundquist, B. (2020). The Bottleneck Hypothesis in L2 acquisition: L1 Norwegian learners' knowledge of syntax and morphology in L2 English. Second Language Research, 36(1), 3-29. https://doi.org/10.1177/0267658318825067

Jiang, N., Novokshanova, E., Masuda, K., \& Wang, X. (2011). Morphological Congruency and the Acquisition of L2 Morphemes. Language Learning, 61(3), 940-967. https://doi.org/10.1111/j.1467-9922.2010.00627.x

Lardiere, D. (1998a). Case and tense in the 'fossilized' steady state. Second Language Research, 14(1), 1-26. https://doi.org/10.1191/026765898674105303

Lardiere, D. (1998b). Dissociating syntax from morphology in a divergent end-state grammar. Second Language Research, 14(4), 359-375. https://doi.org/10.1191/026765898672500216

Lardiere, D. (2000). Mapping features to forms in second language acquisition. In J. Archibald (Ed.), Second language acquisition and linguistic theory (pp. 102-129). Oxford: Blackwell.

Nguyen, B. T., \& Newton, J. (2021). Production of third-person singular -s and be copula in communication tasks by Vietnamese EFL learners: Acquisition order and learner orientation to form. Canadian Journal of Applied Linguistics. Advanced online publication. Retrieved from https://journals.lib.unb.ca-/index.php/CJAL/libraryFiles/downloadPublic/40

Prévost, P., \& White, L. (2000). Missing surface inflection or impairment in second language acquisition? Evidence from tense and agreement. Second Language Research, 16(2), 103-133. https://doi.org-/10.1191/026765800677556046

Wakabayashi, S., Kimura, T., Matthews, J., Akimoto, T., Hokari, T., Yamazaki, T., \& Otaki, K. (2021). Asymmetry between Person and Number Features in L2 Subject-Verb Agreement. In D. Dionne \& L.-A. Vidal Covas (Eds.), Proceedings of the 45th Annual Boston University Conference on Language Development (pp. 735-745). Somerville, MA: Cascadilla Press.

$\mathrm{Wu}, \mathrm{D}$. (2001). A research into interlanguage and its fossilization in second language acquisition. Foreign Language Education, 22(2), 17-22.

Yuan, B. (2001). The status of thematic verbs in the second language acquisition of Chinese: against inevitability of thematic-verb raising in second language acquisition. Second Language Research, 17(3), 248-272. https://doi.org/10.1177/026765830101700302 
Yuan, B. (2003). Are functional categories to blame for the general failure in second language acquisition? Foreign Language Teaching and Research, 35(4), 259-267.

Zobl, H., \& Liceras, J. (1994). Functional categories and acquisition orders. Language Learning, 44(1), 159-180. https://doi.org/10.1111/j.1467-1770.1994.tb01452.x

\section{Notes}

Note 1. We do not distinguish second language acquisition and foreign language learning in this article. Therefore, L2 refers to not only second language, but also foreign language.

\section{Copyrights}

Copyright for this article is retained by the author, with first publication rights granted to the journal.

This is an open-access article distributed under the terms and conditions of the Creative Commons Attribution license (http://creativecommons.org/licenses/by/4.0/). 